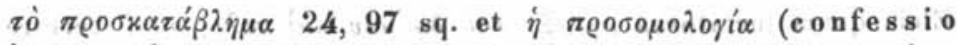
in cumulum addita, G. Schaeferus) et si quae alia sunt eius-

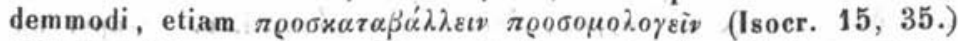
alia uno tenore pronunciata esse demonstrent. Certum est autem aut in omvibus eiusmodi compositis novitiam illam seribendi rationem adhibendam esse aut in nullo. Quid est enim quod

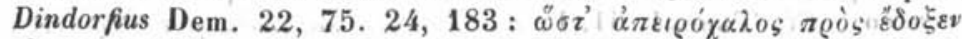

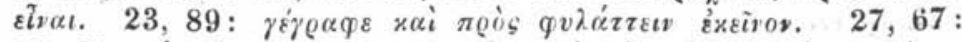

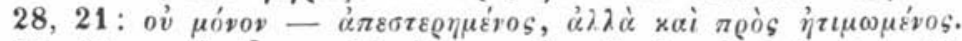

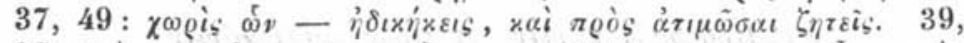

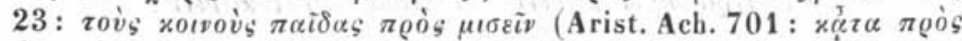

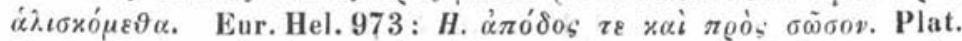

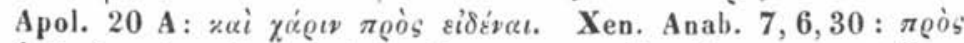

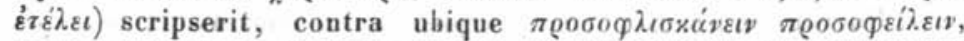
$\pi$ ообофגеiั $(5,5.8,12.23,89.35,46.36,4.6 .10 .12 .58$,

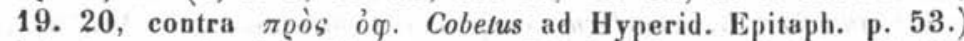
intactum omiserit? Idemque $\pi \varrho 0 \sigma \delta \varepsilon i$ 1, 19. $\pi$

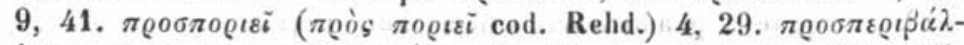

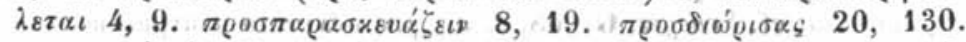

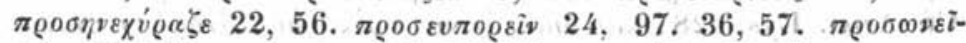

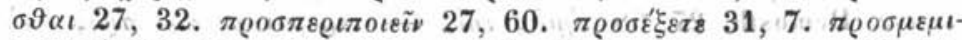

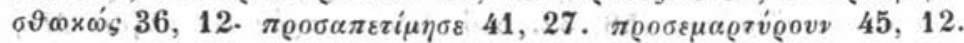

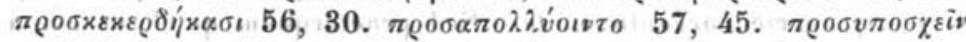
p. 1436, 7. admisit. Quid quod ne in uno quidem eodemque verbo

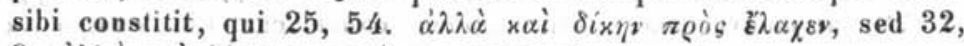

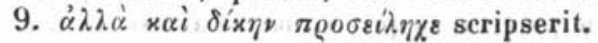

Misnae.

Fr. Franke.

\title{
24. Nachtrag zu den bemerkungen über Hesychius.
}

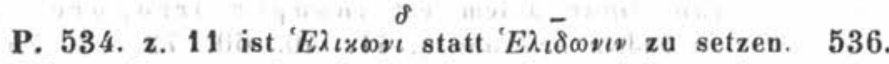
no. 498. noch passender als das deutsche sprichwort konnte das

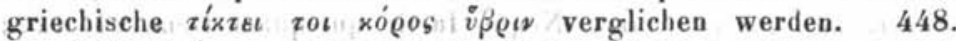
no. 597. $\alpha \rho \infty \mu \alpha z \alpha$ ist vielleicht nicht zu ändern, wenn man $\pi \varepsilon$ -

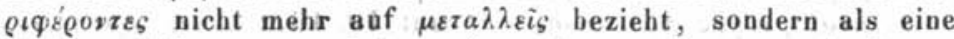
zweite erklärung von $\vartheta v \lambda \alpha x \circ g o ́ \varrho \iota$ nimmt und von sackträgern, die getraide tragen, versteht. 551. no. 623. Пв́vov: $\mu \varepsilon \mu \alpha \lambda \alpha-$

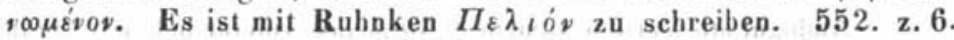
lies $\pi \alpha \sigma \sigma v \delta i \eta \eta$ statt $\pi \alpha \sigma \sigma v \delta i$. Ibid. no. 635. $\left.\varepsilon^{2} x \alpha \dot{\alpha} \lambda \lambda \varepsilon t\right]$ vielleicht

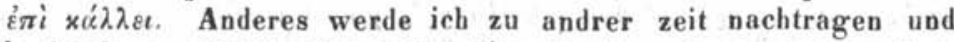
berichtigen. Schliesslich möge hier die bemerkung stehen, dass herr Schmidt oben p. 217 den nachweis geliefert hat, dass von den 293 vorschlägen, die ich im ersten theile dieser ahhandlung (Philol. bd. XII, p. 601) den kritikern zur prüfung vorgelegt 
habe, sieben emendationen bereits, von andern gelehrten gemacht sind. Da es sehr wahrscheinlich ist, dass von den 442 neuen vorsehlägen gleichfalls einige schon von andern gelehrten gemacht sind, so sehe ich mich zu der erklärung veranlasst, dass ich die priorität bereitwilligst jedem zugestehe, dem sie gebührt, und die richtigkeit des von hrn. Schmidt befolgten grundsatzes, nur den ersten finder einer besserung nambaft zu machen, vollkommen anerkenne.

Berlin.

A. Meineke.

\section{Zn Iulius Cäsar.}

Caes. b. c. III, 69: omniaque erant tumultus, timoris, fugae plena, adeo ut, quum Caesar signa fugientium manu prehenderet et consistere iuberet, alii dimissis equis eundem cursum conficerent, alii ex metu eliam signa dimitterent. Man hat an dimissis anstoss genommen; um zu fliehen, gebe niemand sein pferd auf, also könne schon deshalb dimissis equis nicht richtig sein. Faërnus u. a. haben daher admissis equis geschrieben, was M. Haupt aber ebenfalls verwirft, weil hier von reiterei gar nicht die rede sei. Derselbe will daher - er selbst nennt es eine hershafte verbesserung - nihilo sequius lesen (Philol. jahrg. I, p. 587). Meines erachtens ist aber zu einer emendation hier gar kein grund vorhanden, wenn sich auch nicht läugnen lässt, dass admissis equis, obgleich diese änderung weniger herzhaft ist, als die von dimissis equis in nihilo sequius, vollkommen klar und verständlich ist und von fliebenden ganz passend gesagt werden kann. Was zunächst die einwendung Haupt's gegen admissis und somit auch gegen dimissis anbetrifft, dass hier gar nicht von reiterei die rede sei, so halte ich dieselbe für nicht begründet. Allerdings heisst es vorher: equitatus Caesaris, quod angusto itinere per aggeres adscendebat, receptui suo timens, initium fugae faciebat. $\mathrm{Es}$ ist aber, wie aus dem folgenden hervorgeht, hiermit nicht die ganze reiterei gemeint, sondern wenn wohl auch der grössere theil derselben, nur die, welche in der nähe des rechten flügels aufgestellt war, deren flueht daher auch von diesem alsbald bemerkt werden musste. Erst die wahrgenom. mene verwirrung und flucht des rechten flügels erfüllte den lin. ken mit furcht und schrecken und hatte auch dessen rückzug und flucht zur folge. Auch auf dem linken flügel oder in des. sen nähe war reiterei aufgestellt, deren an unserer stelle nicht in derselben weise, wie oben, erwähnung geschah, weil hier nicht von der reiterei der anfang zur flucht gemacht wurde, son, dern diese nur von der allgemeinen verwirrung ergriffen sich ebenfalls durch die flucht zu retten suchte. Aber auch das spe- 